\title{
Cinco trasvases de la Doctrina de Juan de Ávila a otros catecismos
}

\author{
LUIS RESINES LLORENTE \\ Profesor jubilado del Estudio Teológico Agustiniano
}

RESUMEN: La Doctrina cristiana que se canta, asignada a Juan de Ávila, es una caja de sorpresas, desde el momento en que no han dejado de aparecer trasvases parciales de lo que escribió el Apóstol de Andalucía, de los que se sirvieron otros autores. Como la obra de Juan de Ávila aparecía anónima, nadie se tomó la molestia de citar la procedencia de lo que incorporaba a su propio catecismo. Este artículo desvela cinco de esos trasvases, hasta ahora desconocidos, uno en España y cuatro en Portugal.

ABSTRACT: The catechism tittled Doctrina cristiana que se canta, under the name of Juan of Ávila, is a lot of surprises; it again shows new partials apports from the contents that wrote the Apostle of Andalucía; others authors used them. The reason may be that the catechism of Juan of Ávila ist a anonimous booklet. This article shows five new apports until now unknowns, one in Spain, and the four other in Portugal.

PAlabras ClaVe: catecismo, doctrina, Inácio Martins, Juan de Ávila, Marcos Jorge, Pedro Ramiro de Alba.

KEYwords: catechism, doctrine, Inácio Martins, Juan de Ávila, Marcos Jorge, Pedro Ramiro de Alba

La Doctrina Christiana que se canta puede ser asignada a Juan de Ávila, sin absoluta certeza, pues se trata de una edición materialmente anónima. Cuando publiqué la edición crítica de la misma recopilé toda la información disponible, que mostraba con certeza las varias ediciones que se 
llevaron a cabo, así como también los "préstamos" de que se habían apropiado unos y otros autores, sin citar de dónde los habían tomado'.

Resulta casi imposible de imaginar que esta serie de préstamos o apropiaciones no se haya agotado, y que continúen apareciendo en uno y otro lugar. Cierto que los libros más conocidos, o de autores consagrados han sido revisados en más de una ocasión, por lo cual no era previsible que de ellos surgieran sorpresas. Pero, ¿qué pasa con los libros desconocidos, o menos consultados? Pues bien, la consulta de algunas de estas obras ha deparado sorprendentes resultados con hasta cinco aportaciones diversas de este tipo de préstamos literarios.

Prefiero, en primer lugar, ofrecer el panorama conjunto de las partes que han sido trasvasadas y empleadas por otros autores, incorporadas a sus obras respectivas, en la tabla que sigue, en la que destaco con negrita las cinco nuevas localizaciones de fragmentos de la Doctrina de Ávila:

\begin{tabular}{|c|c|c|}
\hline \multicolumn{2}{|c|}{$\begin{array}{c}\text { JUAN DE ÁvILA, Doctrina christiana } \\
\text { que se canta, Valencia, } 1554 \\
\text { Esquema por secciones }\end{array}$} & Reproducciones parciales \\
\hline $1^{\mathrm{a}}$ & Cartilla & --- \\
\hline $2^{\mathrm{a}}$ & Cartilla de la doctrina cristiana & $\begin{array}{l}\text { MARCos JoRge, Doctrina: Todo fiel cris- } \\
\text { tiano, Luego recemos; } \\
\text { Gregorio DE PESQUERA: toda la cartilla } \\
\text { de la doctrina } \\
\text { Julio RoBles, Mandamientos }\end{array}$ \\
\hline $3^{\mathrm{a}}$ & Sermón del día del juicio & Gregorio de PeSQuera \\
\hline $4^{a}$ & Coplas & DIEGO DE LEDESMA \\
\hline $5^{\mathrm{a}}$ & Misterios del Rosario & $\begin{array}{l}\text { MARCOS JORGE /INÁCIO MARTINS: } \\
\text { Cantigas }\end{array}$ \\
\hline $6^{\mathrm{a}}$ & Interrogaciones & $\begin{array}{l}\text { GASPAR ASTETE: Catecismo (parcialmente) } \\
\text { GASPAR DE OlMEDO, Doctrina: } \\
\text { toda la sección } \\
\text { PEDRo RAMIRO DE AlBA, Preguntas (dos } \\
\text { partes) }\end{array}$ \\
\hline $7^{\mathrm{a}}$ & Avisos & InÁCIO Martins: Avisos semejantes \\
\hline
\end{tabular}

${ }^{1}$ Resines, Luis, SAN JUAN DE ÁVILA. Doctrina cristiana que se canta, Khaf, Madrid, 2012. 
El resultado que se sigue del examen de la tabla resulta espectacular, porque, a excepción de la cartilla con el alfabeto, sílabas y ejercicios de silabeo, todo el resto de la Doctrina christiana que se canta, en mayor o menor medida, ha sido utilizado por otros autores que se han apropiado de partes de ella con absoluta impunidad literaria. Es preciso decir en su descargo, que, como la Doctrina asignada a Ávila es anónima, nada sucedía por emplear lo que no llevaba nombre alguno y a nadie pertenecía.

Procede un comentario rápido, a fin de destacar los nuevos descubrimientos. Ya están consignados en la obra referida todo los lugares en que Gregorio de Pesquera, Julio Robles, Diego de Ledesma, Gaspar Astete y Gaspar de Olmedo se sirvieron de la Doctrina de Ávila. Quedan, por consiguiente, cinco nuevos usufructos que han llevado a cabo por un lado Pedro Ramiro de Alba, y por otro, cada uno de ellos por separado en la misma obra, Marcos Jorge e Ignacio Martins, en la doctrina que figura a nombre de ambos.

\section{Pedro Ramiro de Alba}

Fue arzobispo de Granada desde finales de 1526 hasta el 21 de junio de 1528 , en que falleció. Propuesto por Carlos V como arzobispo, y a la espera de las bulas pontificias, asistió a la Junta de la Capilla Real, para examinar y tomar medidas en la cuestión de la conversión de los moriscos, que, como población residual, y en algunas localidades mayoritaria, no terminaba de integrarse con el resto de la población. Pedro Ramiro recibió de Carlos V el encargo de redactar un catecismo pensado específicamente con esa finalidad, y lo llevó a cabo, estructurado en cuatro partes, en que exponía la fe cristiana y rechazaba los defectos de lo que los moriscos no debían creer ni llevar a cabo, para conseguir una conversión plena. La deducción es que este catecismo pudo estar redactado e impreso en 1527 , sin poder precisar fecha ${ }^{2}$.

Cuando años después, en 1568, tuvo lugar en Valencia una reunión de eclesiásticos para afrontar el mismo problema, se redactó un libro, que recoge el catecismo de Pedro Ramiro. A él se añadieron otros tratados que fueron tenidos por prácticos o necesarios, y el libro resultante está integrado por cuatro escritos, diferentes entre sí:

\footnotetext{
${ }^{2}$ Resines, Luis, El catecismo de Pedro Ramiro de Alba (en publicación).
} 
- la Doctrina Christiana, de Pedro Ramiro de Alba,

- las Constituciones que se ordenaron en dicha asamblea,

- la Breue summa y ressolucion de la doctrina Christiana,

- y Algunas preguntas acerca de esta Doctrina Christiana.

Pues bien, el último escrito, que responde al genérico epígrafe de $\mathrm{Al}$ gunas preguntas acerca de esta Doctrina Christiana, incorpora un interrogatorio sin nombre de autor alguno. Ocupa los f. 79v-80v. Y, carente de toda señal identificativa, tal interrogatorio constituye un fragmento de la sección sexta de la Doctrina atribuida a Juan de Ávila. Esta sección consta de cuatro partes, de las cuales aparecen únicamente las dos primeras, en la obra editada en Valencia en 1568.

Son una serie de preguntas que exponen algunas cosas fundamentales de la fe, pero que ni son completas ni suponen en texto armónico. Al constar sólo dos de las cuatro partes de la sección, es evidente que no es un texto completo, $\mathrm{Y}$ al tratarse de un fragmento de una sección de la obra completa asignada a Juan de Ávila, tampoco se puede esperar una presentación íntegra ni orgánica de la fe cristiana. Pero a quienes se reunieron en Valencia en 1568 para entender de la conversión de los moriscos, les pareció que este fragmento podría ser útil, y como tal fue reproducido.

El bloque de preguntas incluye las 11 de la primera parte, y 19 de la segunda parte de la sección de interrogatorio de Ávila; omite 43 preguntas de esta misma segunda parte. Esta referencia numérica sirve para hacerse una idea del carácter fragmentario del apartado que se refiere a las preguntas; el mismo texto indica su función pedagógica cuando señala que "sirven para que se conserven en la memoria".

Estamos ante un bloque errático que fue a parar a este catecismo. Como en Valencia se había editado en 1554 la Doctrina de Juan de Ávila, y posiblemente se llevaron a cabo otras ediciones, resultaban unas preguntas conocidas. Y como se reunieron en Valencia en 1568 quienes las conocían, reprodujeron un parte de las mismas. Afortunadamente se han podido rescatar del olvido, y ha sido posible su identificación y procedencia: la Doctrina de Juan de Ávila.

Una indicación inexcusable: He puesto a nombre de Pedro Ramiro de Alba, por simplificar, el empleo de un fragmento del interrogatorio de Juan de Ávila. Pero la realidad es que, cuando esto sucedió en 1568 en la edición de Valencia, Pedro Ramiro de Alba ya había muerto. La asignación, por tanto, no es a la persona, sino a la obra que lleva su nombre. 


\section{Marcos Jorge e Inácio Martins}

El jesuita portugués Marcos Jorge enseñó, entre otras disciplinas y en diversas localidades, teología moral en el Colegio de Santo Antâo, de Lisboa durante los años 1564 a $1569^{3}$. Durante esos años parece lo más probable -no es fecha segura, sino la más comúnmente aceptada- que en 1566 publicara una Doctrina Christam ordenada a maneira de dialogo pera ensinar os meninos... Tal Doctrina, redactada a base de preguntas y respuestas, se articula en catorce capítulos, en los cuales se desarrollan los principales aspectos doctrinales y morales de la fe cristiana. La obra gozó desde el primer momento del favor de los jesuitas en Portugal, y, como en piña, la difundieron por todos los lugares en que se hallaban presentes, consiguiendo que en muy poco tiempo adquiriera una notable difusión no sólo entre los jesuitas; esto se reflejó en numerosas ediciones, que actualmente resultan difíciles de consignar.

En la edición de Lisboa, Manoel de Lyra, 1592, (Doctrina Christam. Ordenada a maneira de Dialogo, para ensinar os meninos. Pello P. Marcos Jorge, da Companhia de Iesu, Doctor em Theologia. Acrescentada pello P. Inacio Martinz, da mesma Companhia, Doutor Theologo) los preliminares remiten con evidencia a ediciones anteriores no precisadas. Así, la censura, firmada por Bartholomeu Ferreira, el 10 de enero de 1583 (una década antes de la fecha de esa edición lisboeta) señala el informe favorable que emite por encargo del arzobispo de Lisboa; visto lo cual, consta la aceptación para ser impresa (firmada por Iorge Serrâo y Antonio de Mendoça), así como la autorización final, de fecha 13 de abril de 1583, emitida por Christovâo de Matos. Por esas fechas la diócesis estaba vacante, pues el cardenal Enrique de Portugal había sido trasladado a la sede de Évora, y no se había nombrado sucesor.

Se puede, por tanto, hablar con seguridad de una edición de 1583, sin poder ir más lejos en las ediciones que se hubieran sucedido desde la que se supone primera, de 1566. Para 1583, y por supuesto para 1592, existe la plena certeza de que el también jesuita Inácio Martins ${ }^{4}$, llevó a cabo una serie de adiciones al texto de Marcos Jorge; éstas adiciones tuvieron lugar en fecha desconocida.

${ }^{3}$ Vaz de Carvalho, J., “Jorge, Marcos”, en Ch. O’Neill - J. Ma Domínguez (eds.), Diccionario Histórico de la Compañía de Jesús, Roma - Madrid, Institutum Historicum Societatis Jesu - Universidad Pontificia Comillas, 2001, III, 2153-2154.

${ }^{4}$ Vaz de Carvalho, J., “Martins, Inácio”, en Ch. O’Neill - J. Ma Domínguez (eds.), Diccionario Histórico de la Compañía de Jesús, Roma - Madrid, Institutum Historicum Societatis Jesu - Universidad Pontificia Comillas, 2001, III, 2529-2530. 
Si no ha sido alterada la edición, y no hay razones para sospechar de ello, Martins añadió unas "Lembranças pera ensinar a santa Doutrina pelo P. Ignacio (sic) Martins", que figuran en la edición que citaré a continuación, en los f. 1r-4v, y, a continuación de la Doctrina de Marcos Jorge, sin interferir en ella, añadió un voluminoso apéndice que supone otro tanto del volumen de lo escrito por Marcos Jorge: "Siguemse alguns tratados muito deuotos e proveitosos, ordenados pelo P. Ignacio (sic) Martins, Doutor theologo da Companhia de Iesu"; van desde el f. 57r hasta el 107v. Así consta en la edición cuya portada lleva este largo título y descripción: Doctrina Christam [orde]nada a maneira de [dialogo] pera ensinar os meninos. Pelo P. Marcos Jorge da Companhía de Iesu, Doctor em Theologia. Acrescentada pelo P. Ignacio Martins, da mesma Comp. Doct. Theologo. De novo emendada e acrescentada hûa Ladainha de Nossa Senhora, Lisboa, com licencia e priuilegio, Officina Craesbeeckiana, 1655. (BNP, R-16933).

La edición de 1592, a partir de la p. 123, incluye hasta el final, los mismos tratados: "Seguemse cinco tratados muito devotos e proveitosos, ordenados pelo P. Inacio Martins, Doctor Theologo da Companhia de Iesu". Estos cinco tratados son:

- Ordem como um christâo debe gastar o dia;

- Como se ha de ovuir missa, com outras lembranças pertenecentes a Missa;

- Como se ha de confessar o Christâo;

- Como ha um Christâo de comungar;

- Seguemse quatro ladainhas muito deuotas do sanctissimo Sacramento e do suauissimo nome de Iesu e do Spiritosancto, e outras de nossa Senhora que se costumman cantar na sua sancta casa Angelical de Loreto.

Así figura en la edición de 1592, y hay que suponer que así figurara en la edición segura de 1583; pero aunque se aprecian algunos cambios entre las ediciones de 1592 y 1655, con ambas a la vista, nada o casi nada se puede asegurar con certeza sobre la fecha de las aportaciones de Martins, dejando a salvo el bloque directamente catequético de Marcos Jorge.

¿Cuándo se produjeron las adiciones de Martins? Entre la edición supuestamente primera de 1566 , la segura, pero desconocida de 1583 , y la conocida de 1592, no hay fecha exacta. Ahora bien, en la ya aludida reseña biográfica de Martins, no se señala -hábilmente- esa desconocida fecha, y se indica simplemente que "escribió un suplemento al librito de Doutrina Cristâ, del P. Marcos Jorge, que se hizo popular con el nombre de «Cartilha do Mestre Inácio»". Pero sí se indica, entre las obras publicadas, unas Litaniae Sacrosanctae Eucharistiae ac dulcissimi nominis Iesu. Additae item sunt litaniae beatissimae Mariae, quae in alma Lauretana domo decantari solent, 
(Lisboa, 1578). Si para esa fecha tiene listas las letanías de la eucaristía, del nombre de Jesús y de María, es verosímil que haya que pensar en esa fecha, 1578, como el momento en que se produjo el añadido que Martins realizó sobre el catecismo de Marcos Jorge, que circulaba sin añadidos desde 1566; por tanto, unos doce años exento de adiciones.

La secuencia cronológica hoy conocida de estos primeros años de la Doctrina puede ser así:

\begin{tabular}{|l|l|l|l|l|}
\hline \multicolumn{1}{|c|}{1563} & \multicolumn{1}{c|}{1566} & \multicolumn{1}{c|}{1578} & \multicolumn{1}{c|}{1583} & \multicolumn{1}{c|}{1592} \\
\hline $\begin{array}{l}\text { Aportación } \\
\text { de las coplas } \\
\text { de Juan de } \\
\text { Ávila }\end{array}$ & $\begin{array}{l}\text { Primera } \\
\text { edición } \\
\text { (supuesta) de } \\
\text { Marcos Jorge }\end{array}$ & $\begin{array}{l}\text { Adiciones de } \\
\text { Inácio Martins } \\
\text { al catecismo }\end{array}$ & $\begin{array}{l}\text { Edición } \\
\text { segura, } \\
\text { desconocida }\end{array}$ & $\begin{array}{l}\text { Edición de } \\
\text { Lisboa, } \\
\text { Manoel de } \\
\text { Lyra }\end{array}$ \\
\hline
\end{tabular}

Todos estos preliminares, indispensables, permiten situar las aportaciones que desde la Doctrina de Juan de Ávila pasaron a la Doctrina de Marcos Jorge-Inácio Martins.

En el bloque de cuanto fue escrito por Marcos Jorge, articulado en catorce capítulos, en el capítulo II, sobre la señal de la cruz, antes de que comiencen las preguntas de Jorge, aparece la primera importación que procede de Ávila: los conocidos versos "Todo fiel cristiano", traducidos al portugués, y retocados como consecuencia de tener que buscar la adecuada consonancia (propongo la triple redacción: la original y la de las dos ediciones portuguesAs estudiadas, que no coinciden totalmente entre sí):

\begin{tabular}{|c|c|}
\hline $\begin{array}{c}\text { JUAN DE ÁvILA, Doctrina } \\
\text { Christiana que se canta, } \\
\text { Valencia, } 1554\end{array}$ & $\begin{array}{c}\text { MARCOS JORGE, Doctr } \\
\text { christam ordenada a } n \\
\text { neira de Dialogo, Lisb } \\
1592\end{array}$ \\
\hline $\begin{array}{l}\text { Todo fiel christiano } \\
\text { es muy obligado } \\
\text { a tener devoción } \\
\text { de todo coraçon } \\
\text { con la sancta cruz } \\
\text { de Christo nuestra luz } \\
\text { pues en ella } \\
\text { quiso morir } \\
\text { por nos redemir } \\
\text { de la captividad } \\
\text { de nuestro pecado }\end{array}$ & $\begin{array}{l}\text { Todo fiel Christâo } \\
\text { he muy obrigado } \\
\text { a ter devacam } \\
\text { de todo coraçam } \\
\text { a sancta cruz } \\
\text { de Christo nossa luz: } \\
\text { pois nella quis ser } \\
\text { crucificado } \\
\text { para nos liurar } \\
\text { do captiuerio } \\
\text { de nosso peccado. }\end{array}$ \\
\hline
\end{tabular}

\section{Marcos Jorge, Doctrina Christam [orde]nada a maneira de dialogo, Lisboa, 1655}

Todo fiel Christam he muy obrigado a ter devocam de todo coraçam a sancta cruz de Christo nossa luz pois nella quiz ser crucificado para nos livrar do captiverio de nosso peccado 
y del enemigo malo

Y por tanto

te has de acostumbrar

a signar

haziendo tres cruzes: $\mathrm{La}$ primera en la frente, porque nos libre Dios de los malos pensamientos; la segunda en la boca, porque nos libre Dios de las malas palabras; la tercera en los pechos, porque nos libre Dios de las malas obras, diziendo así: Por la señal de la santa , de nuestros enemigos libranos señor Dios nuestro. En el nombre del padre y del hijo y del spiritu sancto. Amen Jesús.

$\begin{array}{ll}\begin{array}{l}\text { E por tanto } \\ \text { nos hauemos }\end{array} & \begin{array}{l}\text { E por tanto } \\ \text { nos avemos } \\ \text { de costumar }\end{array} \\ \text { a benzer e persignar } & \text { a benzer, e persignar } \\ \text { fazendo tres cruzes: } & \text { fazendo tres cruzes: } \\ \text { a primeira na testa, } & \text { a primeira na testa, } \\ \text { porque nos liure Deos } & \text { para que nos liure Deos } \\ \text { dos maos pensamentos; } & \text { dos maos pensamentos; } \\ \text { a segunda na boca, } & \text { a segunda na boca, } \\ \text { porque nos liure Deos } & \text { para que nos liure Deos } \\ \text { das mas palauras; } & \text { das mas palauras; } \\ \text { a terceira nos peitos, } & \text { a terceira nos peitos, } \\ \text { porque nos liure Deos } & \text { para que nos liure Deos } \\ \text { das mas obras. } & \text { das mas obras. }\end{array}$

E por tanto

nos avemos

de acostumar

a benzer, e persignar

fazendo tres cruzes:

a primeira na testa,

para que nos liure Deos

a segunda na boca,

para que nos liure Deos

das mas palauras;

para que nos liure Deos

das mas obras.

No existe la más mínima duda de que el préstamo tiene un origen en la doctrina asignada a Juan de Ávila, y difundida ampliamente por los jesuitas. Marcos Jorge no partía de cero; en el desarrollo de las preguntas y de la enseñanza que transmite es evidente la fuente que ha consultado (como él mismo lo indica en el prólogo: “...E nos depois de ver algûs outras doutrinas e tomar dellas o que nos pareceu fazir a noso proposito, ordenamos esta".) Pero en los versos o cantinela sobre la señal de la cruz, la evidencia no deja lugar a dudas. Las salvedades entre una y otra versión son debidas al ajuste de la versificación, así como en algún caso a erratas de imprenta.

Cuando Marcos Jorge prosigue su obra, en el capítulo III se centra en la oración del padrenuestro, y aquí aparece la segunda incorporación que procede de Juan de Ávila, igualmente en forma de versos. Es preciso advertir que lo que aquí aparece separado, en dos capítulos diversos, en la Doctrina de Ávila aparece seguido, constituyendo una unidad, pero que podía ser presentado con facilidad como dos composiciones separadas, tal como hizo Marcos Jorge y también otros muchos; se aprecian las inevitables modificaciones exigidas por la versificación; además, otros cambios son debido a que lo que en castellano denominamos como "credo", en portugués es siempre conocido como "Credo em Deos Padre", o que la "Salve" pasa a ser en toda ocasión "Salve Raynha": 


\author{
JuAn de Ávila, Doctrina \\ Christiana que se canta, \\ Valencia, 1554 \\ Luego rezemos \\ lo que sabemos \\ lo que la yglesia \\ romana nos muestra \\ hazer y creer \\ Pater noster \\ Ave María \\ Credo y salue regina
}

bien pronunciado creydo y obrado y digamos assi.
Marcos Jorge, Doctrina christam ordenada a maneira de Dialogo, Lisboa, 1592

Logo cantemos
o que sabemos
o que a Igleja
romana ensina
e manda rezar,
creer e obrar
o Padre nosso
a Ave María
a Salue Raynha
o Credo en Deos Padre
os Mandamentos
de nosso Senhor
e de nossa madre
a santa Igreja
todo bem rezado
crido e obrado.

Marcos Jorge, Doctrina

Christam [orde]nada a maneira de dialogo,

Lisboa, 1655

Logo cantemos
o que sabemos
o que a Igleja
romana ensina
e manda rezar,
creer e obrar
o Padre nosso
a Ave María
a Salue Rainha
o Credo en Deos Padre
os Mandamentos
de nosso Señor
e de nossa Madre
a santa Igreja
todo bim rezado
crido e obrado.

A algunos lectores les podría resultar extraña la columna del castellano, pero esto es lo que se encuentra en la edición asignada a Juan de Ávila, de Valencia, 1554; después estos versos fueron modificados en numerosísimas ediciones de lo que se conoció como catecismo de Ripalda, que en realidad era el segundo catecismo que escribió Gaspar Astete.

Tampoco salió del todo incólume la edición portuguesa de 1592, porque, si bien subsistió, como prueba la edición posterior, en la de 1592 están señalados algunos cambios, que, a pesar de todo, no se consolidaron. Así, los seis primeros versos aparecen tachados, como si no se hubieran de repetir (desde "Logo cantemos" hasta “... e obrar"). Además, otra modificación introducida por alguna mano anónima escribió para sustituirlos junto a los cuatro primeros versos: "Log a / ...", una nueva propuesta, castellanizada:"Luego rezemos / Lo que deuemos / Lo que la Iglesia / Romana enseñanos...".

Cuando las adiciones de Inácio Martins se incorporaron al catecismo original de Marcos Jorge, éste dobló su tamaño. He visto alguna referencia que señalaba descuidadamente que le añadió "algunos pasajes"; ; realidad

${ }^{5}$ Drumond, MARIA CÂNDIDA, "Entre heterodoxos e ortodoxos: notas sobre catecismos dialogados na Europa e as colónias no século XVI", en Fénix. Revista de História e Estudio Culturais, 5 (2008) oct-dic., 1-20. 
es que adicionó 100 páginas. Ya he señalado antes los títulos de los cinco tratados con los que Martins pretendió hacer de la Doctrina de Jorge no sólo un libro para el conocimiento teórico, sino un manual práctico para la vida cristiana. El quinto tratado o bloque que añadió, el de las "Ladainhas", es el más desordenado, pues van a parar a él letanías, cantos, coplas,... A partir del folio 78r propone el modo de rezar el rosario, que presenta con una larga exposición; además de rezos comunes, cada uno de los misterios lleva su título, un grabado, un ofrecimiento y una oración conclusiva; esta exposición abarca los f. 78r a 95v.

Y entonces surge la sorpresa, porque a continuación (f. 96r-98v) incluye otro préstamo que se encuentra en la Doctrina asignada a Juan de Ávila, y que ha sido tomado de la misma. Lleva una advertencia previa, elocuente, que habla del papel que jugaron los jesuitas en la repetición, difusión y a la vez manipulación de la doctrina mencionada. Es sabido que numerosos discípulos que lo fueron de Ávila ingresaron después en los jesuitas; llevaban en su memoria, o en papeles sueltos algunas de las cosas que había oído al maestro andaluz, y en algún caso las pusieron por escrito y las imprimieron, sin que Juan de Ávila fuese conocedor de tales ediciones. Otras veces, como en este caso, algunos que pasaron a Portugal llevaron consigo las coplas que constituyen la sección $5^{\mathrm{a}}$ de la Doctrina de Ávila, que versa precisamente sobre los misterios del rosario, y, sin más, lo dieron a conocer en la nación vecina. Inácio Martín da fe de este proceso, así como de la fecha del trasvase en esas palabras introductorias: "Cantigas dos quinze mysterios do Rosario de nossa Senhora, que os Padres da Companhia de Iesu trouxerâo a Portugal na era de 1563". Llama "cantigas" lo que aquí de denominó "coplas"; no proporciona los nombres de los introductores, pero sí su pertenencia a la Compañía de Jesús; señala que lo llevaron a Portugal, aunque no indique la procedencia española, que resulta innegable, pues las "cantigas" aparecen en castellano; también consta la fecha: 1563. Desde entonces puede que se emplearan en forma oral, hasta que, al componer sus adiciones, Martins las pasó al texto impreso.

He aquí, en triple columna, el texto que figura en la edición atribuida a Ávila, y en las adiciones de Martins: 
JUAN DE Ávila, Doctrina

Christiana que se canta, Valencia, 1554

Los quinze mysterios para rezar el Rosario de nuestra señora la virgen Maria: cinco gozosos: cinco dolorosos: y cinco gloriosos.

Los cinco gozosos Virgen sagrada madre de Dios quien en el mundo tal como vos.

Del angel Gabriel fuistes annunciada y hablando con el sobre la embaxada quedastes preñada del hijo de Dios

Y luego que del houistes oydo que sancta Ysabel hauie concebido sin tiempo perdido hos vistes las dos.

De vos en Belen virgen escogida nascio nuestro bien por darnos la vida su carne aterida vestistesla vos.

Pastores y reyes y vos le adorastes y cumpliendo las leyes al templo lleuastes a Simeon alegrastes viendo hombre a su dios.
Marcos Jorge, Doctrina christam ordenada a maneira de Dialogo, Lisboa, 1592

Cantigas dos quinze mysterios do Rosayro de nossa Senhora, que os Padres da Campanhia de Iesv trouxerâo a Portugal, na era de 1563

Os cinco gozosos

Virgen sagrada

madre de Dios

quien en el mundo

tal como vos.

II O primeyro

Del angel Gabriel

fuistes annunciada

y hablando con el

sobre la embaxada

quedastes morada

del hijo de Dios

Quien en el mundo

tal como vos

II Segundo

Y luego que del huuistes oydo que sancta Isabel auia concebido sin tiempo perdido vos vistes las dos.

II Terceiro

De vos en Bethlem virgen escogida nascio nuestro bien por darnos la vida su carne aterida vestistesla vos.

II Quarto

Pastores y reyes y vos le adorastes y cumpliendo las leyes al templo lleuastes a Simeon alegrastes viendo hombre a su Dios.

\section{Marcos Jorge, Doctrina Christam [orde]nada a maneira de dialogo, Lisboa, 1655}

Cantigas dos quinze mysterios do Rosayro de nossa Senhora, que os Padres da Campanhia de Iesv trouxerâo a Portugal, na era de 1563

\section{Los cinco gozosos}

Virgen sagrada madre de Dios quien en el mundo tal como vos.

1. Del angel Gabriel fuistes annunciada y hablando con el sobre la embaxada quedastes morada del hijo de Dios

2. Y luego que del

Vuistes oido que sancta Ysabel auia concebido sin tiempo perdido Vos vistes las dos.

3. De vos en Bethlen virgen escogida nacio nuestro bien por darnos la vida su carne aterida vestistesla vos.

\section{Pastores y reyes} y vos le adorastes y cumpliendo las leyes al templo lleuastes Simeon alegrastes viendo hombre a su dios. 


\author{
Vos y Joseph \\ al niño perdistes \\ tres dias sin el \\ passates muy tristes: \\ y al templo boluistes \\ hallarle los dos.
}

\section{Los dolorosos}

Orando y afflito

en el huerto estaua

vuestro hijo bendito

y sangre sudaba

tambien acceptaua

su muerte por nos.

Atado en columna

açotes sufriendo

sin culpa ninguna

y no resistiendo

esta padeciendo

el hijo de Dios.

Tambien le pusieron corona de espinas las quales rompieron sus sienes diuinas $\mathrm{Y}$ con escopetinas le escupen por nos.

La cruz muy pesada lleuar bien la vistes vos virgen sagrada a aquel que paristes y hablar no podistes entonces los dos.

En la cruz enclauado vuestro hijo hos hablo y al discipulo amado hos encomendo y por madre mando hos tuuiesse el a vos.
II Quinto

Vos y Joseph

al niño perdistes

tres dias sin el

passates muy tristes:

$\mathrm{y}$ al templo boluistes

hallar vuestro Dios.

Los cinco dolorosos

II $O$ primeiro

Orando y afflito

en el huerto estaua

vuestro hijo bendito

y sangre sudaua

tambien aceptaua

su muerte por nos.

II Segundo

Atado en columna

açotes sufriendo

sin culpa ninguna

y no resistiendo

esta padeciendo

el hijo de Dios.

II Terceiro

Tambien le pusieron

corona de espinas

las quales rompieron

sus sienes diuinas

$Y$ con escopetinas

le escupen por nos.

\section{Quarto}

La cruz muy pesada lleuar bien la vistes vos Virgen sagrada a aquel que paristes y hablar no pudistes entonces los dos.

\section{Quinto}

En la cruz enclauado vuestro hijo os hablo $\mathrm{y}$ al discipulo amado os encomendo y por madre mando os tuuiesse el a vos.
5. Vos y Joseph

al niño perdistes

tres dias sin el

passates muy tristes:

al templo boluistes

a allar vuestro Dios.

\section{Os cinco dolorosos}

1. Orando y afflito en el huerto estaua vuestro hijo bendito y sangre sudaba tambien acceptaua su muerte por nos.

2. Atado en columna açotes sufriendo sin culpa ninguna y no resistiendo esta padeciendo el hijo de Dios.

3. Tambien le pusieron corona de espinas las quales rompieron sus sienes diuinas, con escupitinas le escupen por nos.

4. La cruz muy pesada lleuar bien la vistes vos virgen sagrada a aquel que paristes y hablar no pudistes entonces los dos.

5. En la cruz clauado vuestro hijo os hablo y al discipulo amado os encomendo y por madre mmando os tuuiesse a vos. 
Los v. gloriosos.

De su resurreccion muy cierta estuuistes en la qual la passion en gloria boluistes: con triunfo le vistes delante de vos.

Subiendose al cielo vuestro hijo sagrado dexos por consuelo de su apostolado y como en dechado miraron en vos.

Tambien vino luego el espiritu sancto en lenguas de fuego y mudo vuestro llanto en gozo y en canto y en loores de Dios.

Vuestra muerte en el suelo

fue mucho notada y en la corte del cielo de todos cantada venid desseada del hijo de Dios.

Con gran regozijo se os da la corona que deue tal hijo a tan noble persona el cielo hos pregona por madre de Dios. quien en el mundo tal como vos.

Laus Deo.
Os cinco gloriosos. II $\mathrm{O}$ primeiro

De su resurreccion muy cierta estuuistes en la qual la passion en gloria boluistes: con triunfo le vistes delante de vos.

II Segundo

Subiendose al cielo vuestro hijo sagrado dexoos por consuelo de su apostolado y como en dechado miraron en vos.

II Terceiro

Tambien vino luego el espiritu sancto en lenguas de fuego y mudo vuestro llanto en gozo y en canto y en loores de Dios.

II Quarto

Vuestra muerte en el 5. Vuestra muerte en el suelo

fue mucho notada sois en cuerpo y anima al cielo llevada venid desseada del hijo de Dios.

II Quinto

Con gran regozijo se os da la corona que deue tal hijo a tan noble persona el cielo os pregona por madre de Dios.
Os cinco gloriosos.

1. De su resurreccion muy cierta estuuistes en la qual passion en gloria boluistes: con triunfo le vistes delante de vos.

2. Subiendose al cielo vuestro hijo sagrado dexoos por consuelo de su apostolado y como en dechado miraron en vos.

3. Tambien vino luego el espiritosancto en lenguas de fuego y mudo vuestro llanto en gozo y en canto y en loores de Dios. suelo fue mucho notada sois en alma y cuerpo al cielo llevada venid deseada del hijo de Dios.

5. Con gran regozijo se os da la corona que deue tal hijo a tan noble persona el cielo os pregona por madre de Dios.

Finis.

En la edición de Lisboa, 1592, hubo quien anotó algunas modificaciones en tal o cual estrofa. Así, en el quinto misterio gozoso anotó que la propuesta primera: “...y al templo volvistes / hallar vuestro Dios", quedara como "... al templo volvistes / do le hallastes los dos". Y el cuarto misterio 
glorioso también fue objeto de algunos cambios; decía: "Vuestra muerte en el suelo / fue mucho notada, / Sois en cuerpo y alma / al cielo lleuada"; pero fue corregido como "Vuestra muerte en el suelo / fue mucho llorada, / y en la corte del cielo / fue muy festejada / subid desseada / al cielo lleuada".

Si los anteriores trasvases resultan prácticamente idénticos y reconocibles a la perfección, no sucede lo mismo con la otra aportación que llevó a cabo Inácio Martins. Juan de Ávila había dedicado la séptima sección de su Doctrina a una serie de avisos prácticos para ser tenidos en cuenta a la hora de la catequesis. Inácio Martins hizo algo semejante, que situó, no en la segunda parte de la obra, entre sus adiciones, sino al comienzo, tras el prólogo de Marcos Jorge, pero que son suyas sin asomo de duda: "Lembranças pera ensiñar a santa Doutrina pelo P. Ignacio (sic) Martins". Van del f. $1 \mathrm{r}$ al f. $4 \mathrm{v}$, y constan de 11 indicaciones prácticas para el desarrollo de la catequesis, fruto de la experiencia.

$* * * * *$

Hasta aquí lo que dan de sí estas cinco aportaciones inéditas que desde la Doctrina de Juan de Ávila volaron por una u otra razón a diversos catecismos:

$1^{\mathrm{a}}$. Una serie de preguntas, fragmentarias, que fueron a parar a la edición del catecismo de Pedro Ramiro de Alba, en 1568.

2a . El "Todo fiel cristiano..." que incorporó Marcos Jorge, en 1566, como habían hecho otros también.

$3^{\text {a }}$. Los versos "Luego recemos...", que siguieron el mismo camino.

$4^{\mathrm{a}}$. Las coplas de los misterios del rosario, llevadas en 1563 por algunos jesuitas y reutilizadas por Inácio Martins en sus adiciones, presumiblemente datadas en 1578.

5a. Finalmente, las "Lembranças", que, a imitación de Ávila, Martins propuso como consejos prácticos. 